\title{
Evaluating the effectiveness of drawing methods with torsion in the manufacture of carbon wire with UFG structure
}

\author{
V.A. Kharitonov, M.Yu. Usanov ${ }^{\dagger}$ \\ †barracuda_m@mail.ru \\ Nosov Magnitogorsk State Technical University, 38, pr. Lenina, Magnitogorsk, 455000, Russia
}

\begin{abstract}
This article dicussed the methods that allow to get the wire with the UFG structure drawing with deformation torsion application. It is shown that in the rotating monolithic dies possible to change the coefficient of friction, which reduces the drawing force and redistribution of stresses in the wire. However, this is insufficient for structure refinement. Therefore, it was proposed the way of radial-displacement broach that creates in the center of deformation the powerful displacement deformation, that resulting in improved accumulated degree of deformation. Deformation is carried out with the help of a cassette of radial displacement broach, which is installed behind soap tray into place of die-head block that allowing it to set in the current wire-drawing equipment. The article presents the results of modelling in software complex Deform $3 \mathrm{~d}$ in combination on route of the radial-displacement broach and the broaching through a monolithic dies. It is shown that the torsion effectively increases the cumulative degree of deformation, especially if the torsion implement reversely. Additionally, it was conducted a laboratory experiment. The wire steel grade Ст3 has been stretched from 6,69 $\mathrm{mm}$ to $6,00 \mathrm{~mm}$ diameter at a single pass through the cassette of radial-displacement broach, while the average tensile strength was $718 \mathrm{MPa}$, and the average yield strength was $701 \mathrm{MPa}$. Torsion during drawing through the cassette of radial-displacement broaching gives the increase tensile strength on $83 \mathrm{MPa}$ and yield strength on $121 \mathrm{MPa}$ at a single pass, compared with a monolithic die.
\end{abstract}

Keywords: drawing, wire, torsion, modelling, radial-displacement broach.

\section{Оценка эффективности способов волочения с кручением при изготовлении углеродистой проволоки с УМЗ-структурой}

\author{
Харитонов В.А., Усанов М.Ю.† \\ †barracuda_m@mail.ru
}

ФГБОУ ВО «Магнитогорский государственный технический университет им. Г.И. Носова», пр. Ленина, 38, 455000, Магнитогорск, Россия

Рассмотрены способы, позволяющие получать проволоку с ульрамелкозернистой структурой волочением с применением деформации кручения. Показано, что волочением во вращающихся монолитных волоках удается изменить коэффициент трения, что приводит к снижению усилия волочения и перераспределению напряжений в проволоке. Однако, этого недостаточно для измельчения структуры. Поэтому был предложен способ радиально-сдвиговой протяжки, который создает в очаге деформации значительную сдвиговую деформацию, что приводит к повышению накопленной степени деформации. Деформация осуществляется с помощью кассеты радиально-сдвиговой протяжки, которая устанавливается за мыльницей на место волокодержателя, что позволяет ее устанавливать в действующее волочильное оборудование. В статье приведены результаты моделирования в программном комплексе Deform $3 \mathrm{~d}$ при совмещении по маршруту радиально-сдвиговой протяжки и протяжки через монолитные волоки. Показано, что кручение эффективно увеличивает накопленную степень деформации, особенно если кручение осуществлять реверсивно. При этом, при протяжке через радиально-сдвиговую кассету в проволоке повышается накопленная степень деформации, а при протяжке через монолитную волоку - получаем проволоку с высокой точностью геометрических размеров. Кроме того, был проведен лабораторный эксперимент. Проволока из стали марки Ст3 была протянута с диаметра 6,69 мм на диаметр 6,00 за один проход через кассету радиально-сдвиговой протяжки, при этом средний предел прочности составил 718 МПа, а средний предел текучести 701 МПа. Кручение при волочении через кассету радиально-сдвиговой протяжки дает прирост предела прочности на 83 МПа, а предела текучести на 121 МПа за один проход по сравнению с монолитной волокой.

Ключевые слова: волочение, проволока, кручение, моделирование, радиально-сдвиговая протяжка. 
Проволока находит самое широкое применение во всех отраслях промышленности. Она применяется в виде как готовых изделий, так и полуфабрикатов для производства целого ряда метизов: стальные канаты, сварные и тканые сетки, гвозди, шурупы, детали машин, проволочно-кабельные изделия и др. Получение проволоки с равномерной по сечению проволоки с ультрамелкозернистой (УМЗ) структурой является одним из эффективных способов повышения ее конкурентоспособности. Интерес к материалам с УМЗ структурой обусловлен не только их уникальными физико-химическими свойствами высокими прочностью, пластичностью, износостойкостью, а также значительным снижением ресурсов при производстве и применении таких изделий [1].

Основным способом ОМД, применяемым при изготовлении проволоки, является волочение в монолитных волоках. Как известно, волочению соответствуют трехосные разноименные схемы напряженного и деформированного состояний. При волочении заготовка вытягивается в одном направлении - вдоль продольной оси, и в этом случае поворот главной оси тензора деформации относительно этого направления незначителен, что позволяет отнести этот процесс к квазимонотонному [2]. Из-за такого характера течения металла сложно получить высокую накопленную степень деформации. Так, например, чтобы получить степень деформации е $=17 \ldots 18$ волочением, необходимо вытянуть образец в 10 млн. раз [3], что неизбежно приведет к разрушению металла.

В ОМД для получения ультрамелкозернистых структур получили распространение методы интенсивной пластической деформации (ИПД), основными из которых являются равноканальное-угловое прессование (РКУП), кручение под давлением (КД) и свободная ковка. В данных методах ИПД на измельчение структуры влияют такие факторы как скорость деформации, квазигидростатическое давление, масштабный фактор и немонотонный характер деформации [2].

На наш взгляд, наиболее эффективными способами для измельчения структуры при производстве проволоки являются способы, основанные на кручении [4]. Поэтому для получения накопленной степени деформации e $=17 . .18$ процессом РКУП требуется 16 проходов, а кручением под давлением достаточно 0,5...1 оборота [3].

Целью работы является анализ способов получения проволоки волочением с применением кручения и разработка рекомендаций по выбору эффективного способа получения проволоки с УМЗ структурой.

В производстве проволоки деформация кручением получила применение [5-9] при использовании вращающихся волок и вращения переднего и/или заднего концов проволоки, путем установки специальных устройств. Эти способы применяются для снижения усилия волочения и повышения качества проволоки путем управления напряженным состоянием. Влияние кручения на изменение структуры при этом не изучалось.

Известна современная работа [10], в которой на основе моделирования в программном комплексе ABAQUS исследовалось напряженно-деформированное состояние при волочении с вращением волоки. Показано, что вращение меняет картину напряженно-деформированного состояния при волочении, а также приводит к появлению дополнительных деформаций сдвига. Кроме того, при вращении волоки повышается температура, что позволяет совместить операции волочения и термической обработки [11]. Однако, четких рекомендаций и законов изменения структуры выявлено не было.

Известны работы о применении комбинированных процессов деформации, включая кручение, для непрерывного наноструктурирования проволоки [4]. Было показано, что эти процессы позволяют получать требуемую структуру. Однако, оценки влияния деформации кручения при этом не производилось, а для реализации этих процессов в промышленных условиях требуется достаточно сложное дополнительное оборудование.

Нами было проведено исследование влияния кручения переднего и заднего концов проволоки на изменение структуры проволоки в программном комплексе Deform-3d [12]. Так же было проведено исследование в программном комплексе Deform-3d волочение во вращающейся монолитной волоке [13]. Исследовалась одна протяжка с диаметра 5,50 мм на диметр 4,86 мм (обжатие $22 \%$ ). В качестве материала была принята сталь AISI1070 из базы Deform-3d. Модель материала заготовки - упруго-пластическое тело, длинной 50 мм. Геометрия волоки по ГОСТ 9453-75. Скорость волочения - 2 м/с. Коэффициент трения по Кулону 0,05. Соотношение линейной скорости вращения волоки и заготовки принимали $12,5 \%, 25 \%, 50 \%$ и $100 \%$.

После моделирования в продольном сечении заготовки была нанесена координатная сетка с размером ячеек $1 \times 1$ мм. Искажение координатной сетки после волочения во вращающейся волоке с соотношением линейных скоростей 50\% показано на рис. 1.

Анализ полученных данных показывает, что при соотношении скоростей 12,5\% происходит скручивание заготовки со стороны выхода, и угол скручивания составляет 1 град. С повышением числа оборотов вращения волоки, увеличивается угол скручивания заготовки до угла 2,6 град при соотношении линейных скоростей $50 \%$. При соотношении скоростей 100\% происходит закручивание переднего конца заготовки.

T.о. вращение волоки и переднего и заднего концов проволоки приводит к незначительному изменению структуры. Связано это с особенностями волочения в монолитной волоке и действием контактного трения. Волочение осуществляется с минимальным контактным трением, а вращение еще дополнительно его уменьшает. Тем самым снижается вероятность сдвиговой деформации, а для ее реализации необходимо или снижать скорости волочения, или вращать волоку с очень высокими оборотами, что в практике волочения или не экономично, или сложно реализуемо.

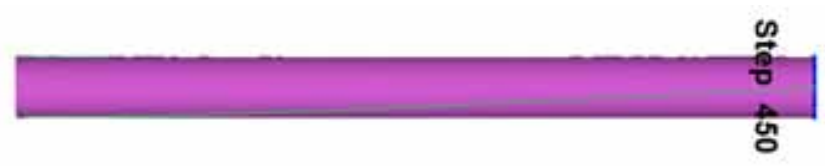

Pис. 1. (Color online) Скручивание заготовки после волочения. Fig. 1. (Color online) Torsion billet after drawing. 
В работах $[14,15]$ проведено исследование по применению волочения со сдвигом. Устройство состоит из волоки, со специальной геометрией, с возможностью вращения вокруг оси волочения. Деформация, сопровождающаяся изменением физико-механических свойств металла и формированием ультрамелкозернистой структуры, обеспечивается за счет того, что устройство снабжено второй неподвижной волокой, а внутренние каналы первой и второй волок выполнены в виде смещенных конусов, причем выходное сечение второй волоки эксцентрично относительно входного сечения первой волоки. Данный способ обеспечивает высокую степень сдвиговой деформации, может применяться на действующем волочильном оборудовании и не требует дополнительных устройств. Однако для его реализации необходим инструмент с достаточно сложной геометрией. Необходимо жестко соблюдать соотношение линейной скорости проволоки и угловой скорости вращения волоки. Данный способ достаточно перспективный и находится на стадии лабораторного исследования.

Качественно новый уровень возможностей по улучшению структуры и свойств любого деформируемого металла открывает принципиально новый способ обработки давлением - процесс радиально-сдвиговой прокатки (РСП), разработанный в НИТУ «МИСиС» [16]. В основе способа лежит траекторное управление движением деформируемого металла. В очаге деформации создается геликоидальное истечение металла с торможением внешнего слоя заготовки и разгоном внутреннего. Разнонаправленные потоки вызывают интенсивные сдвиговые перемещения в объеме проката. Многократно интенсифицируется измельчение структурного строения. Металл приобретает характерное мелкодисперсное строение, практически не доступное для других стационарных способов ОМД [17]. Радиально-сдвиговой прокаткой можно обрабатывать не длинномерные изделия.

В МГТУ им Г.И. Носова с 2001 г. проводятся исследования по применению радиально-сдвиговой деформации для производства проволоки. Используя волочение в качестве основного способа обработки проволоки и заменив монолитную волоку на роликовую, был разработан способ, получивший название - радиально-сдвиговая протяжка (РСПр). РСПр является аналогом радиально-сдвиговой прокатки, как роликовое волочение является аналогом продольной прокатки. Кассета радиально-сдвиговой протяжки устанавливается на стандартной волочильной машине за мыльницей на место волокодержателя.

Процесс радиально-сдвиговой протяжки был смоделирован в программном комплексе Deform-3d [18-20]. C помощью координатной сетки определены траектории течения металла [20]. Металл течет по геликоидальной траектории, которую характеризует угол подъема винтовой линии $\gamma$ (рис. 2).

Угол подъема винтовой линии зависит от угла конической части ролика и от вытяжки. С увеличением вытяжки и обжатия угол скручивания уменьшается, т.е. подобно виткам пружины плотность навивки становится больше. Меняя эти параметры можно управлять характером течения металла, что недостижимо при волочении в монолитных волоках.

Так как траектории течения металла становятся больше то, это приводит к немонотонной деформации и, соответственно, к повышению степени деформации. Что в свою очередь приводит к измельчению структуры металла. Зная угол подъема винтовой линии, можно определить накопленную степень деформации по формуле:

$$
e=2 \ln \left(d_{0} / d\right)+\ln (90 / \gamma),
$$

где $d_{0}$ и $d-$ начальный и конечный диаметры проволоки, соответственно.

С целью исследования влияния РСПр на механические свойства проволоки были проведены лабораторные испытания. В качестве исходной заготовки использовали катанку из стали марки Ст3 диаметром 6,69 мм, которую протянули на диаметр 6,00 мм. Были получены следующие результаты: предел прочности исходной заготовки 429 МПа, а предел текучести 313 МПа. После одной протяжки предел прочности стал 718 МПа, а предел текучести 701 МПа (абсолютный прирост предела прочности и текучести соответственно составил 289 и 388 МПа). По литературным данным [21] при волочении с такой же вытяжкой в монолитной волоке заготовки из Ст3 предел прочности составляет $635 \mathrm{MПа,} \mathrm{а} \mathrm{предел}$ текучести 580 МПа. Отсюда следует, что кручение при волочении в волоке РСПр дает прирост предела прочности на 83 МПа, а предела текучести на 121 МПа за один проход, что объясняется характером течения металла в волоке РСПр.

Сравнительный характер распределения накопленной степени деформации, полученной при моделировании в Deform-3d радиально-сдвиговой протяжки и волочения в монолитной волоке, приведен на рис. 3. Видно, что при РСПр на поверхности накопленная степень деформации достигает значения 4, в то время как при волочении в монолитной волоке этот показатель достигает величины 0,3 .

Накопленная степень деформации при волочении e $=2 \ln (6,69 / 6,00)=0,22$, а при РСПр е $=2 \ln (6,69 / 6,00)+$ $+\ln (90 / 71)=0,45$. Из рис. 3 видно, что данные хорошо согласуются с расчетными результатами Deform-3d, в то время, как данные для РСПр отличаются. Видимо, это связно с тем, что процесс волочения в монолитной волоке хорошо изучен теоретически, а процесс РСПр - нет. При РСПр поверхностные слои подвергаются интенсивной циклической деформации, и поэтому мы получили в Deform-3d такие результаты.

Особый интерес представляет комбинирование радиально-сдвиговой протяжки и волочения в монолитной волоке. Для этого было проведено сравнительное моделирование получения проволоки по маршруту 16,00-14,25-12,85-11,73-10,80-10,00 мм из стали марки Ст80, с различной комбинацией расположения монолитных волок и волок РСПр и направлением вращения последних (табл. 1).

Зависимости изменения углов скручивания в различных комбинированных маршрутах приведены на рис. 4.

Из рис. 4 видно, что в первом проходе угол скручивания составляет $71^{\circ}$. При дальнейшем волочении угол скручивания увеличивается до 76 град (т.е. спираль 
выпрямляется). При РСПр в том же направлении угол скручивания уменьшится до 63 град, а при РСПр в противоположном направлении - до 94 град, т.е. закрутится в обратном направлении.

При волочении по маршруту №4 сначала образуется спираль, а при дальнейшем волочении и реверсивной

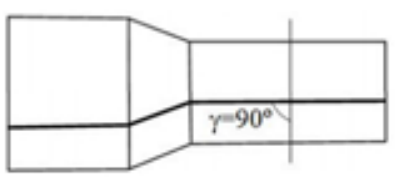

a

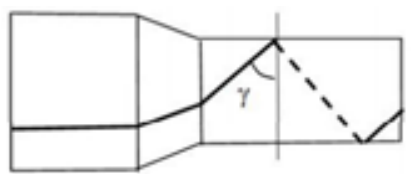

$\mathrm{b}$
Рис. 2. Траектории течения металла при волочении (a), при радиально-сдвиговой протяжке (b).

Puc. 2. The trajectories of the metal flow during drawing (a), in the radial displacement broach (b).

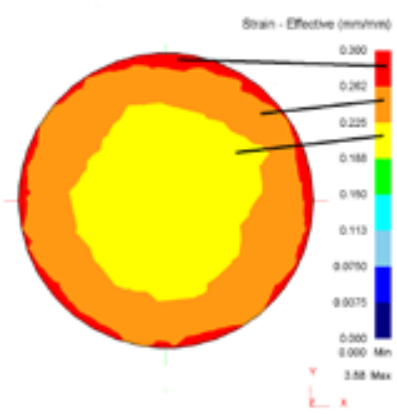

a

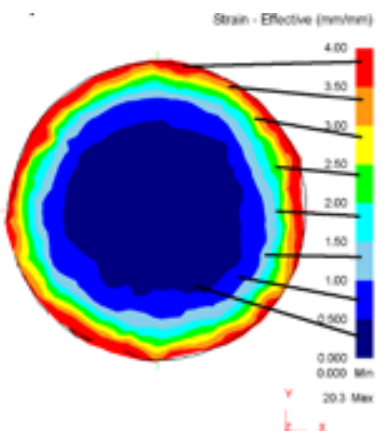

b
Рис. 3. (Color online) Картина распределения накопленной степени деформации полученной в Deform-3d при волочении (a), при радиально-сдвиговой протяжке (b).

Fig. 3. (Color online) The distribution pattern of the srain effective obtained in Deform-3d during drawing (a), in the radial displacement broach (b).
РСПр спираль меняет направление свивки и после волочения в монолитных волоках в двух последних проходах винтовая линия превращается в прямую, как до первого прохода.

Степень деформации при комбинированных маршрутах приведена в табл. 2 .

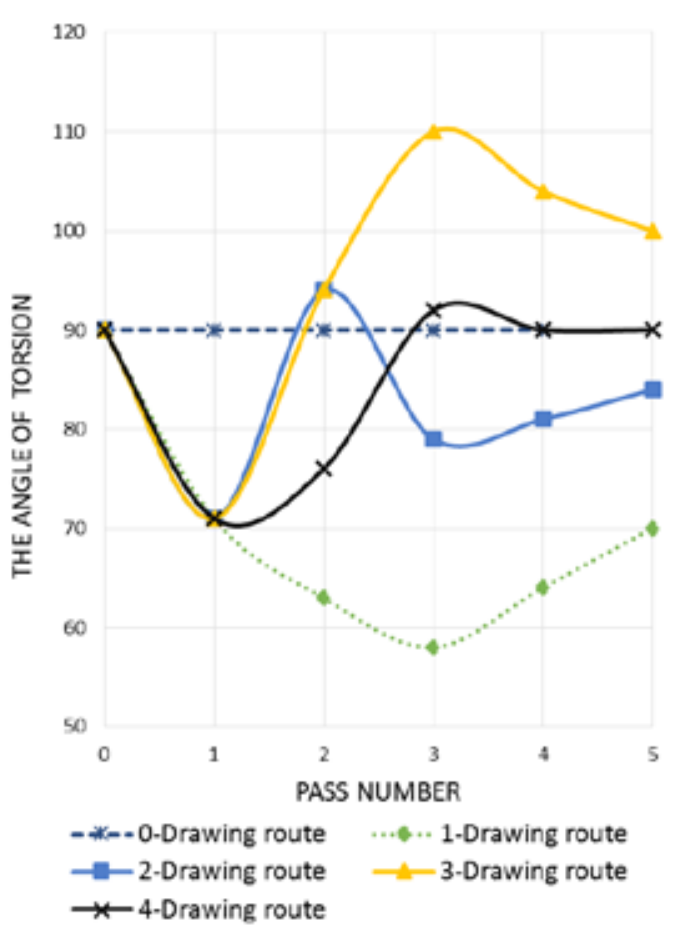

Pис. 4. (Color online) Изменение угла скручивания в различных комбинированных маршрутах.

Fig. 4. (Color online) Change the angle of torsion in a variety of combined routes.

Табл. 1. Комбинирование маршрутов.

Table 1. Combined routes.

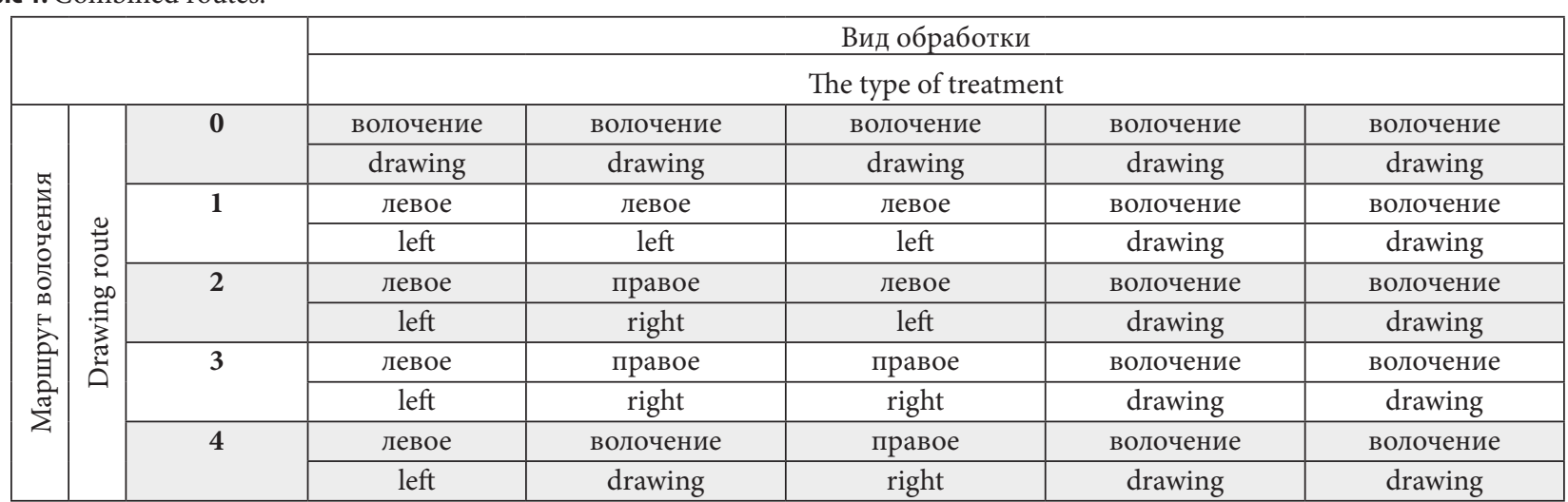

табл. 2. Накопленная степень деформации.

Table 2. Strain effective.

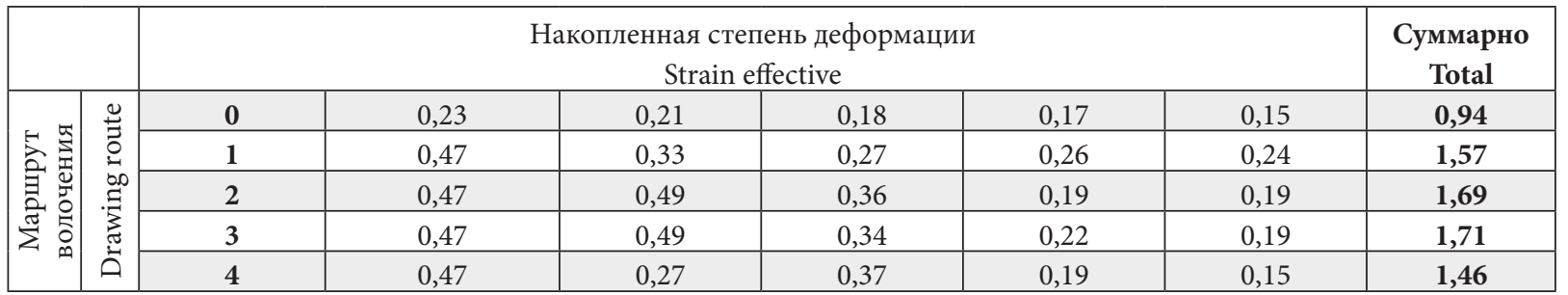


Из таблицы 2 видно, что кручение позволяет значительно повысить накопленную степень деформации в сравнении с волочением в монолитных волоках. Причем, наиболее эффективно увеличивает накопленную степень деформации реверсивное вращение волок радиально-сдвиговой протяжки.

При совмещении двух роликовых волок, вращающихся в разные стороны, был разработан способ изготовления высокопрочной проволочной арматуры периодического профиля, для создания на поверхности проволоки-заготовки мелкодисперсной, равновесной феррито-цементитной структуры. Причем толщина этого слоя зависит от глубины проникновения сдвиговой деформации, которая в свою очередь пропорциональна значению вытяжки [22].

T.о. применение вращающихся монолитных волок и способов вращения переднего и заднего концов проволоки не позволяют проволоку с УМЗ структурой. Для получения такой структуры необходимо задавать интенсивное кручение инструментом, создавая геликоидальное течение металла в очаге деформации. Такими способами являются волочение со сдвигом и радиально-сдвиговая протяжка. Применение РСПр позволяет получить высокую степень накопленной деформации и тем самым высокую прочность проволоки. Совмещая радиально-сдвиговую протяжку с волочением в монолитных волоках, можно получать готовую проволоку с измельченной структурой. Применение волок РСПр не требует модернизации волочильного оборудования и установки дополнительных устройств. Установка волоки РСПр на волочильной машине производится так же как это делается в настоящее время при использовании классических роликовых волок.

Благодарность/Acknowledgements. Результать работы были получены в рамках выполнения госзадания Минобрнауки России № 11.1525.2014K om 18.07.2014

\section{Литература/References}

1. M.A. Polyakova, A.E. Gulin, O.A. Nikitenko, D.V. Konstantinov, M.S. Zherebtsov. Steel №5, 2014. p. 9396. (in Russian) [М.А. Полякова, А.Е. Гулин, О.А. Никитенко, Д.В. Константинов, М.С. Жеребцов. Сталь №5, 2014. С. 93-96]

2. F. Utyashev. Modern methods of intensive plastic deformation. Textbook. Study guide. Ufa, UGATU. (2008) 313 p. (in Russian) [Ф.З. Утяшев. Современные методы интенсивной пластической деформации. Учебное пособие. Уфа, УГАТУ. 2008. 313 с]

3. F. Utyashev. Forging and stamping. Material working by pressure. 2011. №5. p.33-39. (in Russian) [Ф.З. Утяшев. Кузнечно-штамповое производство. Обработка металлов давлением. 2011. №5. С.33-39.]

4. V.A. Kharitonov, M.Yu. Usanov. Processing of solid and laminate materials № 1 (42) July 2015 p. 50-61. (in Russian) [В.А. Харитонов, М.Ю. Обработка сплошных и слоистых материалов № 1 (42) июль 2015. С. 50-61.]

5. Patent USSR № 372002, 01.03.1973. (in Russian) [A.c. CCCP № 372002, 01.03.1973].
6. Patent USSR № 539630, 25.12.1976. (in Russian) [A.c. CCCP № 539630, 25.12.1976].

7. Patent USSR № 663462, 25.05.1979. (in Russian) [A.c. CCCP № 663462, 25.05.1979].

8. Patent USSR № 1243860, 15.07.1986. (in Russian) [A.c. CCCP № 1243860, 15.07.1986].

9. Patent USSR № 2043799, 20.09.1995. (in Russian) [A.c. CCCP 2043799, 20.09.1995].

10. Y. Loginov. Forging and stamping. Material working by pressure. 2014 №6. p.39-41. (in Russian) [Ю.Н. Логинов. Кузнечно-штамповочное производство. Обработка металлов давлением 2014 №6. С.39-41.]

11. Y. Loginov. Interactive IV International scientificpractical conference "Innovations in materials science and metallurgy». Ekaterinburg. (2015). p. 234-238. (in Russian) [Ю.Н. Логинов. IV Международная интерактивная научно-практическая конференция “Инновации в материаловедении и металлургии". - Екатеринбург : Изд-во Урал. ун-та, 2015. - С. 234238.]

12. V.A. Kharitonov, M.Yu. Usanov. Modeling and development of metal forming processes: Intern. Collection of Scient. Articls. Ed. V.M. Salganik. Magnitogorsk: MSTU named after G.I. Nosov, 2012, pp. 82-88. (in Russian) [ В.А. Харитонов, М.Ю. Усанов. Моделирование и развитие процессов обработки металлов давлением: междунар. сб. науч. тр. / под ред. В.М. Салганика. Магнитогорск: Изд-во Магнитогорск. гос. техн. ун-та им. Г.И. Носова, 2015. Вып. 21. С. 82-88.]

13. V.A. Kharitonov, M.Yu. Usanov. Processing of solid and laminate materials № 2 (43) November 2015 p. 38-43. (in Russian) [В.А. Харитонов, М.Ю. Усанов. Обработка сплошных и слоистых материалов №2 (43) ноябрь 2015, c. 38-43.]

14. A. Raab, M. Chukin. Actual problems of physical metallurgy of steels and alloys: materials XXI Ural metallurgists school. Magnitogorsk: Publishing house of Nosov Magnitogorsk state technical university 2012. p. 20-21. (in Russian) [А.Г. Рааб, М.В. Чукин. Актуальные проблемы физического металловедения сталей и сплавов: материалы XXI Уральской школы металловедов-термистов. Магнитогорск: Изд-во Магнитогорск, гос. техн. ун-та им. Г.И. Носова. 2012. C.20-21.]

15. Patent RF №2347632, 27.02.2009. (in Russian) [Патент РФ №2347632, 27.02.2009].

16. I.N. Potapov, P.I. Polukhin, E.A. Kharitonov, S.P. Galkin. Theory and technology of metals: and energy-efficient metal forming processes. Moscow. MISiS. 1986. p. 7278. (in Russian) [И.Н. Потапов, П.И. Полухин, Е.А. Харитонов, С.П. Галкин. Теория и технология металло- и энергосберегающих процессов обработки металлов давлением. Сб. научн. трудов МИСиС, М., Металлургия, 1986, С.72-78.]

17. S.P. Galkin, B.A. Romancev. Engineering practice. №9, 2014. p.58-61 (in Russian) [С.П. Галкин, Б.А. Романцев. Инженерная практика №9, 2014. С.58-61.]

18. M.Yu. Usanov. Modeling and development of metal forming processes: Intern. Collection of Scient.Articls. 
Ed. V.M. Salganik. Magnitogorsk: MSTU named after G.I. Nosov, 2012, p. 80-85. (in Russian) [М.Ю. Усанов. Моделирование и развитие процессов обработки металлов давлением: междунар. сб. науч. тр. / под ред. В.М. Салганика. Магнитогорск: Изд-во Магнитогорск, гос. техн. ун-та им. Г.И.Носова, 2012. C. 80-85.]

19. V.A. Kharitonov, M.Yu. Usanov. Physicochemical aspects of the study of clusters, nanostructures and nanomaterials: Intern. Collection of Scient. Articls. Ed. V.M. Samsonov, N.Y. Sdobnyakova. Tver: Tver. State. University Press, 2012, vol. 4, p. 309-313. (in Russian) [В.А. Харитонов, М.Ю. Усанов. Физико-химические аспекты изучения кластеров, наноструктур и наноматериалов: межвуз. сб. науч. тр. / под общ. ред. В.М.Самсонова, Н.Ю. Сдобнякова. Тверь: Твер. гос. ун-т, 2012. Вып. 4. С. 309-313.]

20. V.A. Kharitonov, M.Yu. Usanov. Vestnik of MSTU named after G.I. Nosov. 2013. №3. p. 69-73. (in Russian) [B.A. Харитонов, М.Ю. Усанов. Вестник МГТУ №3, 2013 С. 69-73.]

21. A. K. Belan. Issledovanie i razrabotka tehnologii izgotovleniya nizkouglerodistoi armaturnoi provoloki prokatkoi v mnogovalkovih kalibrah: Dissertacija na soiskanie stepeni kandidata tehnicheskih nauk. Magnitogorsk. (1981). 173 p. (in Russian) [А. К. Белан. Исследование и разработка технологии изготовления низкоуглеродистой арматурной проволоки прокаткой в многовалковых калибрах: дисс. канд. техн. наук. Магнитогорск. 1981. 173 с]

22. Patent RF №2502573, 27.12.2013. (in Russian) [Патент РФ №2502573, 27.12.2013 